\title{
Diabetic Ketoacidosis: Pattern of Precipitating Causes
}

\author{
Ashraf Uddin Ahmed ${ }^{1}$, Muhammad Abdur Rahim², Md. Raziur Rahman ${ }^{3}$, \\ Reshad Falah Nazim ${ }^{4}$, Khwaja Nazim Uddin ${ }^{5}$ \\ Received: March 12, 2013 Accepted: March 15, 2014
}

\begin{abstract}
Background: Diabetic ketoacidosis (DKA) is one of the most common acute complications of diabetes mellitus (DM). DKA is a recognised presenting feature of type 1 DM, but it commonly complicates previously diagnosed diabetic patients of all types, specially if they get infection or discontinue treatment. Objective: To describe the precipitating causes of DKA. Materials and Methods: This cross-sectional study was done from September to November, 2010 in Bangladesh Institute of Research \& Rehabilitation in Diabetes, Endocrine and Metabolic Disorders (BIRDEM). Diagnosed DKA cases were evaluated clinically and by laboratory investigations for identification of precipitating causes. Results: Out of 50 patients, 28 were female. Mean age was 38.3 years. Forty patients (80\%) were known diabetics and 10 (20\%) were detected diabetic first time during this admission. Severe DKA cases were less common. Infection (20, 40\%) was the commonest precipitating cause followed by noncompliance $(14,28 \%)$. In $7(14 \%)$ cases no cause could be identified. Other less common causes included acute myocardial infarction, acute pancreatitis, stroke and surgery. Conclusion: Infection and noncompliance were the major precipitants of DKA. So, it is assumed that many DKA cases might be prevented by proper counselling regarding adherence to medication and sick days' management.
\end{abstract}

Key words: Diabetes mellitus; Diabetic ketoacidosis; Precipitating causes; Risk factors

J Enam Med Col 2014; 4(2): 94-97

\section{Introduction}

Diabetic ketoacidosis (DKA) is one of the most common, serious and potentially preventable acute complications of diabetes mellitus (DM). ${ }^{1,2}$ Patients with type 1 DM may present with DKA, but more commonly previously diagnosed diabetic patients (both type 1 and type 2) present with this complication. ${ }^{3}$ Cardinal biochemical features include hyperglycaemia, hyperketonaemia and metabolic acidosis. Patients usually present with polyuria, polydipsia, nausea, vomiting, weakness and weight loss. They become dehydrated, hypotensive, tachycardic and dyspnoeic and features of infection may be present. Ultimately they develop coma.
Infection is one of the most common precipitating factors for DKA. ${ }^{1,3}$ Noncompliance to medication is also important. ${ }^{1-3}$ Tissue necrosis such as acute myocardial infarction and stroke can precipitate DKA. ${ }^{2,4}$ In a significant number of patients, no cause can be identified. 1,5

Treatment includes correction of dehydration, hyperglycaemia, electrolyte imbalance and treatment of precipitating cause. With the advent of insulin and modern management facilities, mortality of patients with DKA is now below ten percent. Outcome depends on patients' age, time of treatment initiation, severity of disease, co-morbidities and type of

\footnotetext{
1. Medical Officer, Emergency Department, Bangladesh Institute of Research and Rehabilitation in Diabetes, Endocrine and Metabolic Disorders (BIRDEM), Dhaka

2. Registrar, Department of Medicine, Ibrahim Medical College and BIRDEM, Dhaka

3. Associate Professor, Department of Medicine, Ibrahim Medical College and BIRDEM, Dhaka

4. Lecturer, Department of Pathology, Ibrahim Medical College, Dhaka

5. Professor, Department of Medicine, Ibrahim Medical College and BIRDEM, Dhaka.
}

Correspondence Muhammad Abdur Rahim,Email: muradrahim23@yahoo.com 
underlying cause. ${ }^{6-8}$ In this study, we have evaluated the precipitating causes of DKA in our setting.

\section{Materials and Methods}

This cross-sectional study was done on 50 patients in Bangladesh Institute of Research and Rehabilitation in Diabetes, Endocrine and Metabolic Disorders (BIRDEM), Dhaka, Bangladesh from September to November, 2010. Hospitalised diagnosed DKA cases, previously diagnosed diabetic or undiagnosed, were included in this study from the departments of Internal Medicine and Endocrinology and Intensive Care Unit. Patients having other causes of metabolic acidosis like renal failure were excluded. Severity of DKA was assessed by arterial blood $\mathrm{pH}(<7=$ severe, $7-7.24=$ moderate, $7.25-7.3=$ mild). Data were collected in a preformed, pretested case record form that included patients' demographics, clinical data and laboratory values.

\section{Statistical analysis}

All the data were checked and edited after collection. Then data were analysed with 'SPSS for Windows' version 12.0.

\section{Ethical issue}

Prior to commencement of the study, the protocol was approved by the local Research Approval Committee. The aims and objectives of the study along with its procedure were explained to the patient/party in easily understandable local language and then informed written consent was taken from each patient or relative. They were assured that all information would be kept confidential and be used for research purpose only.

\section{Results}

During the study period, a total of 53 patients got admitted with clinical diagnosis of DKA, but in 3 patients, criteria for DKA were not fulfilled. So, finally 50 patients were included in the study with female predominance (female 28, male 22). Mean age of the patients was $38.3 \pm 15.7$ years. Twenty two (44\%) patients came from villages and rest from urban and sub-urban areas. Most of the patients (47, 94\%) were from middle and lower socio-economic classes.

Table I shows the status of DM of study population. Forty $(80 \%)$ patients were known diabetic and 10 $(20 \%)$ were detected as diabetic first time during this admission. Half of the known diabetic patients (20, $50 \%$ ) were on insulin from the beginning of diagnosis. Ten $(25 \%)$ patients were initially on oral antidiabetic drugs (OAD) followed by insulin and 7 (17.5\%) patients only on oral antidiabetic drugs (OAD). Three (7.5\%) patients were on medical nutrition therapy (MNT). Common presenting features were nausea $(47,94 \%)$, weakness $(46$, $92 \%)$, vomiting $(37,74 \%)$, air hunger $(34,68 \%)$, polydipsia $(34,68 \%)$, polyuria $(31,62 \%)$, fever $(27$, $54 \%)$, blurring of vision $(26,52 \%)$, weight loss $(22$, $44 \%)$, leg cramps $(13,26 \%)$ and drowsiness (16, $32 \%)$. Only 2 (4\%) patients presented with coma. All patients had uncontrolled blood glucose level (Table I). Most of the patients $(40,80 \%)$ had +++ ketonuria at the time of admission. Five (10\%) patients had severe acidosis (Table II). Three $(6 \%)$ patients had severe hyponatraemia and $4(8 \%)$ had hyperkalaemia. In $43(86 \%)$ patients total white cell count was more than $11,000 / \mathrm{mm}^{3}$.

Infection $(20,40 \%)$ was the most common precipitating cause followed by noncompliance $(14,28 \%)$. Other causes were relatively less common (Table III). Causes of infection were urinary tract infection $(13,26 \%)$, pulmonary tuberculosis $(3,6 \%)$, pneumonia $(2,4 \%)$ and liver abscess $(2,4 \%)$.

Table I: Status of DM of the study population $(\mathrm{N}=50)$

\begin{tabular}{|c|c|c|}
\hline Diabetes status & Frequency & Percentage \\
\hline Newly detected DM & 10 & 20 \\
\hline Known DM & 40 & 80 \\
\hline Treatment of known DM & & \\
\hline Insulin & 30 & 75 \\
\hline OAD & 7 & 17.5 \\
\hline MNT & 3 & 7.5 \\
\hline RBS at presentation (mmol & & \\
\hline$<20$ & 0 & 0 \\
\hline $21-25$ & 9 & 18 \\
\hline $26-30$ & 15 & 30 \\
\hline $31-35$ & 25 & 50 \\
\hline$>35$ & 1 & 2 \\
\hline $32.1 \pm 7.5$ & & \\
\hline $\operatorname{HbAlc}(\%)$ & & \\
\hline$<8.5$ & 2 & 4 \\
\hline $8.6-10$ & 10 & 20 \\
\hline$>10$ & 38 & 76 \\
\hline $12.3 \pm 2.5$ & & \\
\hline
\end{tabular}


Table II: Severity of DKA ( $=50)$

\begin{tabular}{|l|c|c|}
\hline $\mathrm{pH}$ & Frequency & Percentage \\
\hline$<7$ & 5 & 10 \\
$7-7.24$ & 29 & 58 \\
\hline $7.25-7.3$ & 16 & 32 \\
\hline
\end{tabular}

Table III: Precipitating causes of DKA

\begin{tabular}{|l|c|c|}
\hline Causes & Frequency & Percentage \\
\hline Infection & 20 & 40 \\
$\quad$ UTI & 13 & 26 \\
$\quad$ Pulmonary tuberculosis & 3 & 6 \\
$\quad$ Pneumonia & 2 & 4 \\
$\quad$ Liver abscess & 2 & 4 \\
\hline Noncompliance & 14 & 28 \\
$\quad$ Omission of insulin & 11 & 22 \\
$\quad$ Reduction of insulin dose & 3 & 6 \\
Myocardial infarction & 4 & 8 \\
Stroke & 2 & 4 \\
Pancreatitis & 2 & 4 \\
Surgery & 1 & 2 \\
Unidentified & 7 & 14 \\
\hline
\end{tabular}

\section{Discussion}

This study was done to find out precipitating causes of DKA. Over half of the patients were females. Female:male was 7.2:5.7 in Denmark. ${ }^{7}$ In Taipei, it was found that $67 \%$ DKA patients were females. ${ }^{9}$ In one recent study in Bangladesh it was found that DKA occurred more commonly among females. ${ }^{3}$ It indicates that, in resource poor societies, compliance to medical treatment for chronic diseases like DM is a difficult task specially for poor village women. In a small study in paediatric age group in India, it was found that DKA occurred twice more commonly among males. ${ }^{10}$

The typical features of polyuria, polydipsia and weight loss which are the predominant features of DKA were relatively less common than nausea, weakness and vomiting in our study. Features of infection, e.g., fever were also common. Status of diabetes control was very poor, mean $\mathrm{HbAlc}$ was over $12 \%$. Only 2 patients had $\mathrm{HbA} 1 \mathrm{c}<8 \%$. These cases were precipitated by acute pancreatitis. In a study in Nairobi over $90 \%$ patients had HbA1c $>8 \%{ }^{11}$

In this study, most patients with mild to moderate acidosis did not have gross electrolyte imbalance. Most of the patients had normal or slightly low sodium levels, high normal or slightly elevated potassium levels. Similar results were found in a study in Pakistan. ${ }^{12}$ In this study three patients had severe hyponatraemia, 4 patients had severe hypokalaemia and 5 patients had severe acidosis. But, after treatment initiation, many patients developed hypokalaemia. In two different studies similar observations were found. ${ }^{7,13}$

In this study almost all patients had neutrophilic leukocytosis, but documented infection was present in $40 \%$ cases. In another study more than $65 \%$ patients had leukocytosis and in 55\% patients there was no infection. ${ }^{14}$

Infection was the commonest precipitating cause in this study. Noncompliance was the second most common cause. In seven cases no cause was found and other causes were relatively less common. Rahim et al found one-third of patients had infection, one-third had noncompliance to insulin treatment and in one-fourth cases no cause was identified. ${ }^{3}$ In a study in Nairobi $34 \%$ cases were precipitated by omitting insulin, $23.4 \%$ cases had infection. ${ }^{11}$ Noncompliance was the most common cause in India $^{2}$ and Korea ${ }^{8}$ whereas in one study in Pakistan ${ }^{12}$ infection precipitated DKA in $63 \%$ cases of type 2 diabetes mellitus.

The present study had some limitations. Limited number of patients were evaluated over a short period. Patients were not definitely classified as having type 1 or type 2 diabetes. Treatment monitoring and outcomes were not evaluated.

In conclusion, it can be said that DKA occurred more commonly in known diabetic patients who had got infection or omitted/reduced the dose of insulin. New cases were not uncommon. Typical features were less common. The glycaemic control in these patients was poor. Severe acidosis and gross electrolyte imbalance were less common. Leukocytosis was common, even in absence of infection. It is anticipated that many DKA cases can be prevented by educating the patients regarding drug compliance and sick days' management. 


\section{References}

1. Mudly S, Rambiritch V, Mayet L. An identification of the risk factors implicated in diabetic ketoacidosis (DKA) in type 1 and type 2 diabetes mellitus. SA Fam Pract 2007; 49(10): 15 .

2. Rao VD, Pradhan B, Mallikarjuna Y, Reddy R. Clinical profile of diabetic ketoacidosis in adults. Nepal Journal Online 2012; 10(2): 80-86.

3. Rahim MA, Uddin KN, Zaman S, Musa AKM, Rahman MR, Hossain MD et al. Clinical spectrum and management of diabetic ketoacidosis: experience in a tertiary care hospital. Birdem Med J 2011; 1(1): 15-20.

4. Umpierrez GE, Kitabchi AE. Diabetic ketoacidosis: risk factors and management strategies. Treat Endocrinol 2003; 2(2): 95-108.

5. Barski L, Nevzorov R, Rabaev E, Jotkowitz AB, Boehm $\mathrm{IH}$, Zektser $\mathrm{M}$ et al. Diabetic ketoacidosis: clinical characteristics, precipitating factors and outcomes of care. IMAJ 2012; 14(5): 299-303.

6. Hardern RD, Quinn ND. Emergency management of diabetic ketoacidosis in adults. Emer Med J 2003; 20(3); 210-213.

7. Henriksen OM, Prahl JB, Roder ME, Svendsen OL. Treatment of diabetic ketoacidosis in adults in Denmark: a national survey. Diabetes Res Clin Pract 2007; 77(1): 113-119.
8. Ko SH, Lee WY, Lee JH, Kwon HS, Lee JM, Kim SR et al. Clinical characteristics of diabetic ketoacidosis in Korea over the past two decades. Diabet Med 2005; 22(4): 466-469.

9. Lin SF, Lin JD, Huang YY. Diabetic ketoacidosis: comparisons of patient characteristics, clinical presentations and outcomes today and 20 years ago. Chang Gunh Med J 2005; 28(1): 24-30.

10. Jahagirdar RR, Khadilkar VV, Khadilkar AV, Lalwani SK. Management of diabetic ketoacidosis in PICU. Indian J Pediatr 2007; 74(6): 551-554.

11. Mbugua PK, Otieno CF, Kayima JK, Amayo AA, McLigeyo SO. Diabetic ketoacidosis: clinical presentation and precipitating factors at Kenyatta National Hospital, Nairobi. East Afr Med J 2005; 82(12 Suppl): 191-196.

12. Jabbar A, Farooqui K, Habib A, Islam N, Haque N, Akhter J. Clinical characteristics and outcomes of diabetic ketoacidosis in Pakistani adults with type 2 diabetes mellitus. Diabet Med 2004; 21(8): 920-923.

13. Rahim MA, Rouf R, Ashrafuzzaman SM, Zaman S, Uddin KN, Rahman MR et al. Presentation, precipitating factors, management and outcome of diabetic ketoacidosis: a tertiary care hospital experience. Bangladesh Med Coll J 2012; 17(2): 65-71.

14. McClarty DG, Kinabo L, Swai AB. Diabetes in tropical Africa: a prospective study, 1981-7.2: course prognosis. BMJ 1990; 300: 1107-1111. 